\title{
STRATEGI PENGEMBANGAN USAHATANI GULA KELAPA DI KECAMATAN PURING KABUPATEN KEBUMEN
}

\author{
Wahid Abdil Malik, Minar Ferichani, Emi Widiyanti \\ Program Studi Agribisnis, Fakultas Pertanian, Universitas Sebelas Maret Surakarta \\ Jalan Ir. Sutami No. 36 A Kentingan Surakarta 57126 Telp./Fax (0271) 637457 \\ E-mail: wahidabdil354@student.uns.ac.id
}

\begin{abstract}
This study aims to determine the magnitude of farm income coconut sugar in District Puring Kebumen, knowing internal factors (strengths and weaknesses) and external (opportunities and threats), to formulate a possible strategic alternatives and identifies priorities for the strategy to be applied in the development of farming of palm sugar in District Puring Kebumen. The research method used is descriptive method. Data analysis method used is the Revenue Analysis, Internal Factor Evaluation (IFE), External Factor Evaluation (EFE), SWOT Analysis and QSPM. These results indicate that the amount of income of Rp 37,323,400.00 for the period June 2015 - June 2016. Internal Factor Evaluation (IFE) showed that coconut sugar farm has five strengths and four weaknesses. External Factor Evaluation (EFE) show gardens coconut sugar farm has four opportunities and five threats. SWOT Analysis generate alternative strategies that can be implemented that improve product with open innovation and their consumer confidence, create attractive packaging so that the consumer response is high, increase competitiveness through cooperatives or associations for joint marketing, and to expand the market by leveraging information technology such as the Internet. QSPM produce good strategic priorities to be implemented is to increase competitiveness through cooperatives or associations for joint marketing.
\end{abstract}

Keywords: Farming, EFE, IFE, QSPM, SWOT

\begin{abstract}
Abstrak: Penelitian ini bertujuan mengetahui besarnya pendapatan usahatani gula kelapa di Kecamatan Puring Kabupaten Kebumen, mengetahui faktor-faktor internal (kekuatan dan kelemahan) dan eksternal (peluang dan ancaman), merumuskan alternatif strategi yang memungkinkan dan mengetahui prioritas strategi untuk diterapkan dalam pengembangan usahatani gula kelapa di Kecamatan Puring Kabupaten Kebumen. Metode penelitian digunakan adalah deskriptif. Metode analisis data yang digunakan adalah Analisis Pendapatan, Internal Factor Evaluation (IFE), External Factor Evaluation (EFE), Analisis SWOT dan QSPM. Hasil penelitian ini menunjukan bahwa besarnya pendapatan sebesar Rp 37.323.400,00 pada periode Juni 2015 - Juni 2016. Internal Factor Evaluation (IFE) menunjukkan usahatani gula kelapa tersebut memiliki lima kekuatan dan empat kelemahan. External Factor Evaluation (EFE) menunjukkan kebun usahatani gula kelapa tersebut memiliki empat peluang dan lima ancaman. Analisis SWOT menghasilkan alternatif strategi yang dapat diterapkan yaitu meningkatkan produk dengan terbukanya inovasi dan adanya kepercayaan konsumen, membuat kemasan yang menarik supaya respon konsumen tinggi, meningkatkan daya saing melalui koperasi atau asosiasi untuk pemasaran bersama, dan melakukan perluasan pasar dengan memanfaatkan teknologi informasi berupa internet. QSPM menghasilkan prioritas strategi yang baik untuk diterapkan adalah meningkatkan daya saing melalui koperasi atau asosiasi untuk pemasaran bersama.
\end{abstract}

Kata kunci: Usahatani, EFE, IFE, QSPM, SWOT 


\section{PENDAHULUAN}

Produk perkebunan yang banyak ditemui dalam keseharian masyarakat Indonesia salah satunya adalah tanaman kelapa. Tanaman kelapa memiliki banyak manfaat yang memberikan nilai tambah pada pendapatan masyarakat. Hampir semua bagian dari tanaman kelapa dapat dimanfaatkan, mulai dari akar sampai nira kelapa yang dapat digunakan sebagai obatobatan, papan, atap rumah, berbagai kerajinan tangan, bahan bakar, maupun media cetak gula kelapa. Salah satunya nira yang keluar dari tangkai bunga digunakan sebagai bahan baku utama pembuatan gula kelapa (Rizki, 2014).

Gula kelapa bisa dikonsumsi sebagai bahan pemanis untuk makanan ataupun minuman sebagaimana bahan pemanis yang lain seperti gula pasir, gula aren, gula siwalan, dan sebagainya, namun juga digunakan sebagai bahan baku pada beberapa industri pangan antara lain kecap dan minuman instan. Dibanding dengan beberapa jenis gula yang lain gula kelapa memiliki kelebihan maupun kekurangan. Gula kelapa memiliki aroma yang khas yang bisa dianggap sebagai kekurangan maupun sebagai kelebihan. Aroma tersebut membuat gula kelapa kurang cocok digunakan untuk pemanis pada bahan pangan yang sensitif terhadap aroma tertentu, namun di sisi lain aroma tersebut juga disukai oleh sebagian konsumen (Rizki, 2014).

Salah satu Kabupaten yang memanfaatkan tanaman kelapa dan turunannya menjadi produk unggulan yaitu Kabupaten Kebumen. Kabupaten Kebumen merupakan kabupaten yang terletak di Propinsi Jawa Tengah yang terletak di dataran rendah dan pantai. Produk turunan tanaman kelapa di Kabupaten Kebumen yang memiliki ekonomi tinggi adalah gula kelapa. Tanaman kelapa yang diolah menjadi gula kelapa umumnya disebut kelapa deres. Nira yang dihasilkan berasal dari penyadapan bunga tanaman kelapa yang merupakan bahan utama pembuatan gula kelapa.

Berdasarkan data Tabel 1 bisa diketahui Kecamatan Puring memiliki produksi deres dan sekaligus produksi gula kelapa yaitu dalam 28.875 batang pohon kelapa deres menghasilkan gula kelapa sebanyak 30.300,54 kuintal.

Tabel 1. Produksi Kelapa Deres dan Gula Kelapa di Kabupaten Kebumen Tahun 2014

\begin{tabular}{clccc}
\hline \multirow{2}{*}{ No } & Kecamatan & $\begin{array}{c}\text { Luas Area Perkebunan } \\
\text { Kelapa (Ha) }\end{array}$ & $\begin{array}{c}\text { Pohon Kelapa } \\
\text { Deres (Btg) }\end{array}$ & $\begin{array}{c}\text { Gula Kelapa } \\
\text { (Kwt) }\end{array}$ \\
\hline 1 & Ayah & 1.329 & 81.75 & $88.690,62$ \\
2 & Buayan & 1.267 & 14.012 & $16.692,75$ \\
3 & Puring & 1.721 & 28.875 & $30.300,54$ \\
4 & Petanahan & 2.635 & 24.254 & $23.698,39$ \\
5 & Klirong & 2.768 & 13.753 & $13.477,80$ \\
6 & Buluspesantren & 1.034 & 15.626 & $14.845,49$ \\
7 & Ambal & 1.358 & 11.876 & $13.725,80$ \\
8 & Mirit & 1.77 & 11.378 & $11.149,75$ \\
9 & Bonorowo & 629 & 4.876 & $4.778,59$ \\
10 & Prembun & 1.214 & 1.508 & $1.531,08$ \\
11 & Rowokele & 1.624 & 12.756 & $12.852,85$ \\
12 & Sempor & 1.932 & 8.877 & $10.465,11$ \\
13 & Karanganyar & 702 & 8.502 & $8.356,08$ \\
14 & Karanggayam & 1.172 & 2.627 & $2.024,48$ \\
15 & Sadang & 610 & 628 & 483,36 \\
16 & Karangsambung & 895 & - & - \\
\hline
\end{tabular}

Sumber data: Dinas Kehutanan dan Perkebunan Kabupaten Kebumen 
Luas area perkebunan kelapa, Kecamatan Puring lebih unggul dibanding Kecamatan Ayah, yang bisa digunakan untuk memperbanyak tanaman kelapa deres yang ada pada Kecamatan Puring.

Berdasarkan latar belakang di atas, dapat dirumuskan permasalahan yang akan dikaji sebagai berikut (1) Berapa besarnya pendapatan usahatani gula kelapa di Kecamatan Puring Kabupaten Kebumen? (2) Apa saja faktorfaktorinternaldaneksternalbagiusahatani gula kelapa di Kecamatan Puring Kabupaten Kebumen? (3) Alternatif strategi apa saja yang memungkinkan untuk diterapkan dalam pengembangan usahatani gula kelapa di Kecamatan Puring Kabupaten Kebumen? (4) Prioritas strategi apa yang memungkinkan untuk diterapkan dalam pengembangan usahatani gula kelapa di Kecamatan Puring Kabupaten Kebumen?

Tujuan dari penelitian ini adalah (1) Mengetahui besarnya pendapatan usahatani gula kelapa di Kecamatan Puring Kabupaten Kebumen. (2) Mengetahui faktor-faktor internal dan eksternal bagi usahatani gula kelapa di Kecamatan Puring Kabupaten Kebumen. (3) Merumuskan alternatif strategi yang memungkinkan untuk diterapkan dalam pengembangan usahatani gula kelapa di Kecamatan Puring Kabupaten Kebumen. (4) Mengetahui prioritas strategi yang memungkinkan untuk diterapkan dalam pengembangan usahatani gula kelapa di Kecamatan Puring Kabupaten Kebumen.

\section{METODE PENELITIAN}

Metode yang digunakan penelitian ini adalah metode deskriptif. Menurut Totok Mardikanto (2011), dalam arti sempit penelitian deskriptif diartikan sebagai penelitian yang hanya menunjukan gambaran, uraian atau rincian tentang gejala atau objek yang akan diteliti. Penelitian ini dilakukan pada bulan Juni 2016 dengan menggunakan data primer.

Lokasi penelitian dipilih secara sengaja (purposif), yaitu obyek yang dipilih karena alasan-alasan diketahuinya sifat-sifat obyek itu (Totok Mardikanto, 2011). Penelitian ini dilakukan pada usahatani gula kelapa yang berlokasi di Kecamatan Puring Kabupaten Kebumen.
Penentuan key informan dalam penelitian ini dilakukan secara sengaja atau purposive sampling dengan mempertimbangkan nara sumber yang dipilih memiliki kontribusi yang besar dalam perumusan strategi pengembangan usahatani gula kelapa di Kecamatan Puring Kabupaten Kebumen. Key Informan yang dipilih yakni Kepala Dinas Perindustrian dan Perdagangan Kabupaten Kebumen, prosuden gula kelapa, konsumen gula kelapa, pedagang gula kelapa, dan pengepul gula kelapa. Kelima key informan tersebut memberikan bobot dan nilai untuk matriks IFE dan EFE dan pemberian nilai QSPM dilakukan oleh Kepala Dinas Perindustrian dan Perdagangan Kabupaten Kebumen.

\section{HASIL DAN PEMBAHASAN}

\section{Kondisi Umum Lokasi Penelitian}

Kabupaten kebumen secara administrative terbagi menjadi 26 Kecamatan, salah satunya adalah Kecamatan Puring. Kecamatan Puring terbagi menjadi 23 Desa, $98 \mathrm{RW}, 120 \mathrm{RT}$, dan 1241 Dusun. Terletak antara $7^{0}-8^{\prime}$ Lintang Selatan dan $-107^{0}-110^{\prime}$ Bujur Timur. Untuk batas wilayahnya sebagai berikut:

Sebelah Utara : Kecamatan Kuwarasan, Kecamatan Adimulyo

Sebelah Timur : Kecamatan Petanahan

Sebelah Selatan : Samudra Hindia

Sebelah Barat : Kecamatan Buayan

Kecamatan Puring merupakan Kecamatan yang terletak di daerah pesisir pantai, sekitar $30 \mathrm{Km}$ jarak dari Kota Kebumen. Dari 23 Desa hanya 4 desa yang memproduksi gula kelapa dan diambil 3 desa yaitu Tambakmulyo, Surorejan, dan Sidoharjo.

\section{Pendapatan Usahatani Gula Kelapa Biaya usahatani}

Usahatani adalah bentuk pengorganisasian dan pengelolaan aset serta tata cara yang dilakukan dalam bidang pertanian dengan tujuan untuk menambah kesejahteraan dan memperbaiki taraf kehidupan petani (Hanna, 2014).

Biaya tetap

Biaya tetap dalam usahatani gula kelapa adalah penyusutan, pajak tanah dan bangunan, serta listrik. 
Tabel 2. Biaya Tetap Rata-rata Usahatani Gula Kelapa di Kecamatan Puring Kabupaten Kebumen Juni 2015 - Juni 2016

\begin{tabular}{lc}
\hline \multicolumn{1}{c}{ Nama Biaya Tetap } & Jumlah Biaya (Rupiah) \\
\hline Penyusutan & 3.453 .100 \\
Pajak Tanah dan Bangunan & 30.5 \\
Listrik & 296 \\
\hline Total Biaya Tetap & $\mathbf{3 . 7 7 9 . 6 0 0}$ \\
\hline
\end{tabular}

Sumber: Analisis Data Primer, 2016

\section{Biaya variabel}

Tabel 3. Biaya Variabel Rata-rata Pengeluaran Usahatani Gula Kelapa di Kecamatan Puring Kabupaten Kebumen Juni 2015 Juni 2016

\begin{tabular}{clc}
\hline No & \multicolumn{1}{c}{ Biaya } & Jumlah (Rp) \\
\hline 1 & Nira & 0 \\
2 & Obat Gula & 720 \\
3 & Transportasi & 549 \\
4 & Kayu Bakar & 270 \\
5 & Sekam & 486 \\
6 & Lain-lain (minyak dan gula pasir) & 720 \\
\hline & Total Biaya Variabel & $\mathbf{2 . 7 4 5 . 0 0 0}$ \\
\hline
\end{tabular}

Sumber: Analisis Data Primer, 2016

Biaya total rata-rata produksi usahatani gula gula kelapa di Kecamatan Puring Kabupaten Kebumen dari 30 responden adalah sebagai berikut:

$$
\begin{aligned}
& \text { TC }=\text { TFC }+ \text { TVC } \\
& \begin{aligned}
\text { TC } & =\operatorname{Rp} 3.779 .600+\operatorname{Rp} 2.745 .000 \\
& =\operatorname{Rp} 6.524 .600,00
\end{aligned}
\end{aligned}
$$

\section{Penerimaan}

Tabel 4. Penerimaan Rata-rata Hasil Penjualan Gula Kelapa di Kecamatan Puring Kabupaten Kebumen pada Juni 2015 - Juni 2016

\begin{tabular}{llccc}
\hline No & Produk & $\begin{array}{c}\text { Jumlah Harga per } \\
(\mathbf{K g})\end{array}$ & Kg (Rp) & Jumlah (Rp) \\
\hline \multirow{1}{1}{$\begin{array}{l}\text { Gula Kelapa } \\
\text { Batok }\end{array}$} & 3.132 & 14 & 43.848 .000 \\
\hline \multicolumn{2}{l}{ Total } & & & $\mathbf{4 3 . 8 4 8 . 0 0 0}$ \\
\hline
\end{tabular}

Sumber: Analisis Data Primer, 2016

\section{Pendapatan}

Tabel 5. Pendapatan Rata-rata Usahatani Gula Kelapa Di Kecamatan Puring Kabupaten Kebumen pada Juni 2015 - Juni 2016

\begin{tabular}{ccr}
\hline No & Jenis & \multicolumn{1}{c}{ Total } \\
\hline 1 & Penerimaan & 43.848 .000 \\
2 & Biaya Total & 6.524 .600 \\
\hline & Pendapatan & $\mathbf{3 7 . 3 2 3 . 4 0 0}$ \\
\hline
\end{tabular}

Sumber: Analisis Data Primer, 2016

\section{Karakteristik Gula Kelapa \\ Produsen Gula Kelapa}

Penelitian ini dilakukan dengan wawancara kepada 30 produsen gula kelapa, pengepul, pedangan pengecer, rumah makan, ibu rumah tangga, dan dinas perindustrian dan perdagangan. Lama usahatani gula kelapa di Kecamatan Puring Kabupaten Kebumen ratarata adalah 7 tahun. Sebagian besar usia produsen adalah 35 samapi 40 tahun, dengan tingkat pendidikan yang rendah yaitu SMP. Pengusaha gula kelapa umumnya memiliki karakteristik berupa industri skala rumah tangga dengan tenaga kerja berasal dari anggota keluarga.

\section{Proses Produksi Gula Kelapa}

Produsen gula kelapa di Kecamatan Puring tidaklah sulit mencari bahan baku nira.Setiap pagi hari sekitar pukul 06.00-08.00 mengambil hasil deresan, pukul 08.00-16.00 memasak nira dan pencetakan, dan pukul 16.00 memangkas manggar pohon kelapa yang akan diambil niranya dikeesokan harinya. dikeesokan harinya.

\section{Analisis Faktor Internal dan Eksternal}

Berdasarkan hasil analisis faktor internal dan eksternal maka dapat diidentifikasikan kekuatan, kelemahan, peluang dan ancaman. Adapun faktor-faktor tersebut yaitu identifikasi faktor kekuatan: bahan baku mudah didapatkan, proses produksi mudah, modal tercukupi, produsen terbuka terhadap inovasi, dan kualitas produk tinggi; identifikasi faktor kelemahan: jumlah produksi tidak menentu, kemasan produk kurang menarik, belum ada pemanfaatan teknologi informasi dan alat produksi masih tradisional; identifikasi faktor peluang: permintaan tinggi, respon penduduk 
baik, kepercayaan konsumen tinggi, dan tumbuhnya kesadaran konsumen mengkonsumsi pangan organik; dan identifikasi faktor ancaman: pengaruh cuaca terhadap kualitas produk buruk, peran nyata pemerintah kurang dirasakan produsen, tidak adanya koperasi atau asosiasi untuk pemasaran bersama, kurangnya sarana prasarana jalan, dan adanya gula cor sebagai pesaing pasar.

\section{Analisis Matriks IFE dan Matriks EFE}

Berdasarkan analisis lingkungan eksternal dan internal tersebut dapat diidentifikasikan ke dalam faktor-faktor yang memiliki pengaruh terhadap kesuksesan atau kegagalan pada kegiatan pengembangan usahatani gula kelapa di Kecamatan Puring Kabupaten Kebumen. Identifikasi faktor-faktor terdapat pada tabel 6, yang dirangkum dalam matriks IFE dan EFE.
Berdasarkan Tabel 6 dapat diketahui bahwa posisi internal usahatani gula kelapa di Kecamatan Puring Kabupaten Kebumen termasuk rata-rata, hal ini ditunjukan dengan nilai total skor bobot sebesar 2,9215. Nilai ini menunjukan bahwa posisi internal usahatani gula kelapa cukup kuat dimana kekuatan yang ada sudah dapat mengatasi kelemahan di usahatani gula kelapa tersebut. Berdasarkan Tabel 7 dapat diketahui bahwa sentra gula kelapa di Kecamatan Puring memiliki potensi yang responsive untuk menghadapi ancaman. Hal ini ditunjukan dengan nilai skor bobot yaitu 2,886, sehingga usahatani gula kelapa dapat dikatakan cukup berhasil, mampu menarik keuntungan dari peluang eksternal dan menghindari ancaman yang menghadang usahataninya.

$\underline{\text { Tabel 6. Matriks IFE Usahatani Gula Kelapa di Kecamatan Puring Kabupaten Kebumen }}$

\begin{tabular}{|c|c|c|c|c|}
\hline No & Faktor-faktor Stategi Internal & Bobot & Rating & Bobot $x$ Rating \\
\hline 1 & Bahan baku mudah didapatkan & 0,1376 & 3 & 0,4128 \\
\hline 2 & Proses produksi mudah & 0,1294 & 3 & 0,3882 \\
\hline 3 & Modal tercukupi & 0,1551 & 3 & 0,4653 \\
\hline 4 & Produsen terbuka terhadap inovasi & 0,1380 & 4 & 0,5520 \\
\hline 5 & Kualitas produk tinggi & 0,1725 & 4 & 0,6900 \\
\hline 6 & Jumlah produksi tidak menentu & 0,0689 & 2 & 0,1378 \\
\hline 7 & Kemasan produk kurang menarik & 0,0518 & 1 & 0,0518 \\
\hline 8 & Belum ada pemanfaatan teknologi informasi & 0,0692 & 1 & 0,0692 \\
\hline \multirow[t]{2}{*}{9} & Alat produksi masih tradisional & 0,0775 & 2 & 0,1550 \\
\hline & Tot: & 1,000 & & 29,215 \\
\hline
\end{tabular}

Sumber: Analisis Data Primer, diolah

Tabel 7. Matriks EFE Usahatani Gula Kelapa di Kecamatan Puring Kabupaten Kebumen

\begin{tabular}{|c|c|c|c|}
\hline Faktor-faktor Stategi Eksternal & Bobot & Rating & Bobot x Rating \\
\hline 1 Permintaan tinggi & 0,1889 & 4 & 0,7556 \\
\hline 2 Respon penduduk baik & 0,1508 & 3 & 0,4524 \\
\hline 3 Kepercayaan konsumen tinggi & 0,1417 & 3 & 0,4251 \\
\hline 4 Tumbuhnya kesadaran konsumen mengkonsumsi pangan organik & 0,1599 & 4 & 0,6396 \\
\hline 5 Pengaruh cuaca terhadap kualitas produk buruk & 0,0473 & 1 & 0,0473 \\
\hline 6 Peran nyata pemerintah kurang dirasakan produsen & 0,0944 & 2 & 0,1888 \\
\hline 7 Tidak adanya koperasi atau asosiasi untuk pemasaran bersama & 0,0568 & 1 & 0,0568 \\
\hline 8 Kurangnya sarana prasarana jalan & 0,0849 & 2 & 0,1698 \\
\hline \multirow[t]{2}{*}{9 Adanya gula cor sebagai pesaing pasar } & 0,0753 & 2 & \\
\hline & 1,000 & & 2,886 \\
\hline
\end{tabular}

Sumber: Analisis Data Primer, diolah 


\section{Analisis Matriks IE}

Matriks IE adalah alat untuk menentukan posisi suatu perusahaan didasarkan pada analisis eksternal internal perusahaan(David, 2004). Berdasarkan nilai yang dibobotkan dalam matriks IFE dan matriks EFE, sehingga dapat diketahui potensi usahatani gula kelapa di Kecamatan Puring Kabupaten Kebumen dalam matriks IE yang terdapat paga gambar dibawah ini.

\section{TOTAL RATA-RATA TERTIMBANG IE}

\begin{tabular}{|c|c|c|c|}
\hline Internal & Kuat & Rata-rata & Lemah \\
\hline Eksternal & 4,00 & 3,00 & 1,00 \\
\hline $\begin{array}{l}\text { Tinggi } \\
3,00\end{array}$ & I & II & III \\
\hline $\begin{array}{l}\text { Rata-rata } \\
2,00\end{array}$ & IV & V & VI \\
\hline $\begin{array}{l}\text { Rendah } \\
1,00\end{array}$ & VII & VII & IX \\
\hline
\end{tabular}

Gambar 1. Matriks IE Usahatani Gula Kelapa di Kecamatan Puring Kabupaten Kebumen
Nilai total skor rata-rata pada matriks IFE sebesar 2,9215, sedangkan matriks EFE sebesar 2,886 . Hasil dari pencocokan nilai tersebut diketahui bahwa usahatani gula kelapa berada pada sel $\mathrm{V}$ yang merupakan strategi pertahankan dan pelihara. Strategi yang dapat diterapkan pada sel $\mathrm{V}$ adalah strategi penetrasi pasar dan pengembangan produk.

\section{Analisis Matriks SWOT}

Analisis SWOT (Strength, Weakness, Opportunities, Threats) adalah salah satu teknik untuk merumuskan strategi terbaik (Kalpande $e t$ $a l, 2010)$. Beberapa alternatif strategi yang dapat di gunakan untuk mengembangkan usahatani gula kelapa di Kecamatan Puring Kabupaten Kebumen, antara lain:

Tabel 8. Alternatif Strategi Matriks SWOT Pengembangan Usahatani Gula Kelapa Kecamatan Puring Kabupaten Kebumen

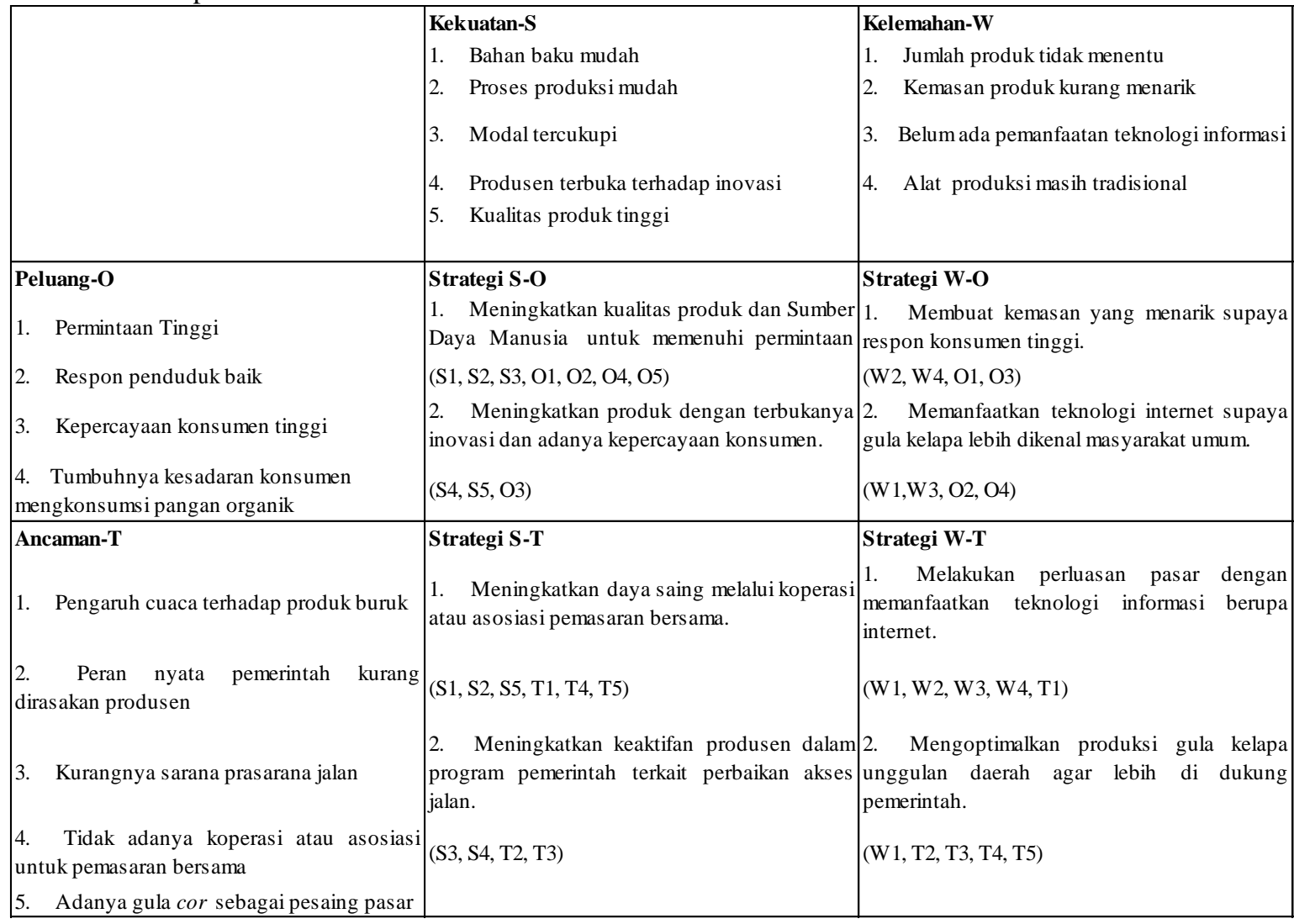

Sumber: Analisis Data Primer, diolah

$\begin{array}{lll}\text { Keterangan : } & \mathrm{S}=\text { Strenght } & \mathrm{O}=\text { Opportunity } \\ & \mathrm{W}=\text { Weakness } & \mathrm{T}=\text { Threats }\end{array}$


Prioritas Strategi (Analisis Matriks QSP)

Quantitative Strategic Planning Matrix (QSPM) menggambarkan alternatif strategi terbaik yang dapat digunakan dari hasil analisis faktor internal eksternal (IE) dan analisis SWOT (Sevenpri dan Linda, 2014). Strategi SWOT menghasilkan delapan alternatif strategi untuk mengembangkan usahatani gula kelapa di
Kecamatan Puring Kabupaten Kebumen. Empat alternatif terbaik yang dipilih dari delapan alternatif strategi yang didapatkan dari matriks SWOT dengan pertimbangan bahwa terbaik dapat dilaksanakan oleh setiap produsen. Strategi yang dipilih masuk ke QSPM. Strategi tersebut adalah:

Tabel 9. Qualitative Strategi Planning Matrix (QSPM) Pengembangan Usahatani Gula Kelapa di Kecamatan Puring Kabupaten Kebumen

\begin{tabular}{|c|c|c|c|c|c|c|c|c|c|c|}
\hline \multirow{3}{*}{ No } & \multirow{3}{*}{ Faktor-faktor Strategi } & \multirow{3}{*}{ Bobot } & \multicolumn{6}{|c|}{ Alternatif Strategi } & \multirow{2}{*}{\multicolumn{2}{|c|}{4}} \\
\hline & & & \multicolumn{2}{|r|}{1} & \multicolumn{2}{|r|}{2} & \multicolumn{2}{|r|}{3} & & \\
\hline & & & $\mathrm{AS}$ & TAS & $\mathrm{AS}$ & TAS & $\mathrm{AS}$ & TAS & $\mathrm{AS}$ & TAS \\
\hline \multicolumn{11}{|c|}{ Faktor Kunci Internal } \\
\hline 1 & Bahan baku mudah didapatkan & 0,1376 & 2 & 0,2752 & 3 & 0,4128 & 4 & 0,5504 & 1 & 0,1376 \\
\hline 2 & Proses produksi mudah & 0,1294 & 3 & 0,3882 & 2 & 0,2588 & 4 & 0,5176 & 1 & 0,1294 \\
\hline 3 & Modal tercukupi & 0,1551 & 1 & 0,1551 & 2 & 0,3102 & 3 & 0,4653 & 4 & 0,6204 \\
\hline 4 & $\begin{array}{l}\text { Produsen terbuka terhadap } \\
\text { inovasi }\end{array}$ & 0,1380 & 2 & 0,2760 & 3 & 0,4140 & 4 & 0,5520 & 1 & 0,1380 \\
\hline 5 & Kualitas produk tinggi & 0,1725 & 3 & 0,5175 & 1 & 0,1725 & 3 & 0,5175 & 4 & 0,6900 \\
\hline 6 & Jumlah produksi tidak menentu & 0,0689 & 2 & 0,1378 & 1 & 0,0689 & 3 & 0,2067 & 4 & 0,2756 \\
\hline 7 & Kemasan produk kurang menarik & 0,0518 & 2 & 0,1036 & 3 & 0,1554 & 4 & 0,2072 & 1 & 0,0518 \\
\hline 8 & $\begin{array}{l}\text { Belum ada pemanfaatan teknologi } \\
\text { informasi }\end{array}$ & 0,0692 & 3 & 0,2076 & 2 & 0,1384 & 4 & 0,2768 & 1 & 0,0692 \\
\hline 9 & Alat produksi masih tradisional & 0,0775 & 4 & 0,3100 & 3 & 0,2325 & 1 & 0,0775 & 2 & 0,1550 \\
\hline Tot: & al Bobot & 1,000 & & 29,482 & & 21,635 & & 33,710 & & 29,220 \\
\hline \multicolumn{11}{|c|}{ Faktor Kunci Eksternal } \\
\hline 1 & Permintaan tinggi & 0,1889 & 3 & 0,5667 & 2 & 0,3778 & 4 & 0,7556 & 1 & 0,1889 \\
\hline 2 & Respon penduduk baik & 0,1508 & 3 & 0,4524 & 2 & 0,6032 & 4 & 0,6032 & 1 & 0,1508 \\
\hline 3 & Kepercayaan konsumen tinggi & 0,1417 & 2 & 0,2834 & 1 & 0,1417 & 3 & 0,4251 & 4 & 0,5668 \\
\hline 4 & $\begin{array}{l}\text { Tumbuhnya kesadaran konsumen } \\
\text { mengkonsumsi pangan organic }\end{array}$ & 0,1599 & 3 & 0,4797 & 1 & 0,1599 & 4 & 0,6396 & 2 & 0,3198 \\
\hline 5 & $\begin{array}{l}\text { Pengaruh cuaca terhadap kualitas } \\
\text { produk buruk }\end{array}$ & 0,0473 & 3 & 0,1419 & 1 & 0,0473 & 4 & 0,1892 & 2 & 0,0946 \\
\hline 6 & $\begin{array}{l}\text { Peran nyata pemerintah kurang } \\
\text { dirasakan produsen }\end{array}$ & 0,0944 & 3 & 0,2832 & 1 & 0,0944 & 2 & 0,1888 & 4 & 0,3776 \\
\hline 7 & $\begin{array}{l}\text { Tidak adanya koperasi atau } \\
\text { asosiasi untuk pemasaran bersama }\end{array}$ & 0,0568 & 2 & 0,1136 & 4 & 0,2272 & 3 & 0,1704 & 1 & 0,0568 \\
\hline 8 & Kurangnya sarana prasarana jalan & 0,0849 & 1 & 0,0849 & 4 & 0,3396 & 2 & 0,1698 & 3 & 0,2547 \\
\hline 9 & $\begin{array}{l}\text { Adanya gula cor sebagai pesaing } \\
\text { pasar }\end{array}$ & 0,0753 & 3 & 0,2259 & 4 & 0,3012 & 1 & 0,0753 & 2 & 0,1506 \\
\hline \multicolumn{2}{|c|}{ Total Bobot } & $\mathbf{1 , 0 0 0}$ & & 26,317 & & 19,907 & & 32,170 & & 21,606 \\
\hline \multicolumn{3}{|c|}{ Total nilai Daya Tarik } & & 50,027 & & 41,542 & & 65,880 & & 44,276 \\
\hline \multicolumn{3}{|c|}{ Tipe Strategi } & & S-O & & W-O & & S-T & & $\mathbf{W}-\mathbf{T}$ \\
\hline
\end{tabular}

Sumber: Analisis Data Primer, diolah 
Keterangan:

$\begin{array}{ll}\text { AS } & =\text { Atractiveness Score } \\ \text { TAS } & =\text { Total Attractiveness Score } \\ \text { Strategi } 1 & =\text { Meningkatkan produk dengan } \\ & \text { terbukanya inovasi dan adanya } \\ & \text { kepercayaan konsumen }\end{array}$

Strategi 2 = Membuat kemasan yang menarik supaya respon konsumen tinggi

Strategi $3=$ Meningkatkan daya saing melalui koperasi atau asosiasi untuk pemasaran bersama

Strategi $4=$ Melakukan perluasan pasar dengan memanfaatkan teknologi informasi berupa internet

Berdasarkan hasil perhitungan QSPM yang telah dilakukan seperti yang tertulis dalam tabel di atas dapat diketahui bahwa strategi meningkatkan produk dengan terbukanya inovasi dan adanya kepercayaan konsumen memperoleh total nilai sebesar 5,0027. Strategi membuat kemasan yang menarik supaya respon konsumen tinggi memperoleh total nilai 4,1542. Strategi melakukan perluasan pasar dengan memanfaatkan teknologi informasi berupa internet memperoleh nilai sekor 4,4276. Sedangkan untuk strategi meningkatkan daya saing melalui koperasi atau asosiasi untuk pemasaran bersamamemperoleh nilai skor 6,5880. Hasil perhitungan tersebut menunjukan bahwa strategi yang paling baik untuk diterapkan diantara keempat strategi yang ada adalahmeningkatkan daya saing melalui koperasi atau asosiasi untuk pemasaran bersama. Strategi meningkatkan daya saing melalui koperasi atau asosiasi untuk pemasaran bersama di usahatani gula kelapa di Kecamatan Puring Kabupaten Kebumen untuk mengembangkan usahanya karena memiliki Total Attractiveness Score (TAS) tertinggi.

\section{KESIMPULAN DAN SARAN}

\section{Kesimpulan}

Berdasarkan hasil penelitian mengenai Strategi Pengembangan Gula Kelapa Di Kecamatan Puring Kabupaten Kebumen, didapatkan kesimpulan (1) Besarnya biaya total yang dikeluarkan oleh usahatani gula kelapa di Kecamatan Puring Kabupaten Kebumen pada bulan Juni 2015 sampai Juni 2016 sebesar Rp 6.524.600,00, penerimaan sebesar $\mathrm{Rp}$ 43.848.000,00, maka pendapatannya sebesar Rp
37.323.400,00. (2) Faktor-faktor internal dan eksternal yang menjadi kekuatan, kelemahan, peluang dan ancaman dalam pengembangan usahatani gula kelapa di Kecamatan Puring Kabupaten Kebumen adalah (a) Faktor-faktor internal yang menjadi kekuatan adalah bahan baku mudah didapatkan, proses produksi mudah, modal tercukupi, produsen terbuka terhadap inovasi, dan kualitas produk tinggi.(b) Faktor-faktor internal yang menjadi kelemahan adalah jumlah produk tidak menentu, kemasan produk kurang menarik, belum ada pemanfaatan teknologi informasi dan alat produksi masih tradisional. (c) Faktor-faktor eksternal yang menjadi peluang adalah permintaan tinggi, respon penduduk baik, kepercayaan konsumen tinggi, dan tumbuhnya kesadaran konsumen mengkonsumsi pangan organik. (d) Faktor-faktor eksternal yang menjadi ancaman adalah pengaruh cuaca terhadap kualitas produk buruk, peran nyata pemerintah kurang dirasakan produsen, tidak adanya koperasi atau asosiasi untuk pemasaran bersama, kurangnya sarana prasarana jalan, dan adanya gula cor sebagai pesaing pasar.(3) Alternatif strategi yang dapat diterapkan dalam pengembangan usahatani gula kelapa di Kecamatan Puring Kabupaten Kebumen yaitu (a) Strategi S-O yaitu meningkatkan kualitas produk dan Sumber Daya Manusia untuk memenuhi permintaan pasar dan meningkatkan produk dengan terbukanya inovasi dan adanya kepercayaan konsumen. (b) Strategi W-O yaitu membuat kemasan yang menarik supaya respon konsumen tinggi dan memanfaatkan teknologi internet supaya gula kelapa lebih dikenal masyarakat umum. (c) Strategi S-T yaitu meningkatkan daya saing melalui koperasi atau asosiasi untuk pemasaran bersama dan meningkatkan keaktifan produsen dalam program pemerintah terkait perbaikan akses. (d) Strategi W-T yaitu melakukan perluasan pasar dengan memanfaatkan teknologi informasi berupa internet dan mengoptimalkan produksi gula kelapa unggulan daerah agar lebih di dukung pemerintah. (4) Prioritas strategi yang dapat diterapkan dalam pengembangan usahatani gula kelapa di Kecamatan Puring Kabupaten Kebumen berdasarkan matriks QSP adalah meningkatkan daya saing melalui koperasi atau asosiasi untuk pemasaran bersama. 


\section{Saran}

Berdasarkan kesimpulan yang didapatkan dari penelitian Strategi Pengembangan Usahatani Gula Kelapa Di Kecamatan Puring Kabupaten Kebumen dapat diberikan saran adalah produsen dan pedagang gula kelapa yang ada di Kecamatan Puring Kabupaten Kebumen seharusnya mengadakan koperasi atau asosiasi untuk pemasaran gula kelapa bersama. Koperasi juga bisa sebagai wadah belajar bersama, bekerja sama, menghadapi masalah bersama dan bisa merubah posisi tawar sehingga mendapat harga gula kelapa yang lebih baik.

\section{DAFTAR PUSTAKA}

David, F. R. 2004. Manajemen Strategi Konsep. Terjemah Edisi 12. Salemba Empat. Jakarta.

Kalpande, S. Gupta, R. Dandekar, M. 2010. A SWOT Analysis Of Small And Medium Scale Enteprises Implementing Total Quality Management. International Journal of Business, Management and Social Sciences, 1(1): 59-64.
Mardikanto, Totok. 2011. Metoda Penelitian dan Evaluasi Agribisnis. Jurusan/ Program Studi Agribisnis Fakultas Pertanian Universitas Sebels Maret. Surakarta.

Nurhasanah, Hanna. 2014. Pengaruh Usahatani Gula Kelapa Terhadap Tingkat Kesejahteraan Pengrajin Gula Kelapa Di Kecamatan Cikalong Kabupaten Tasikmalaya. Jurusan Pendidikan Geografi Fakultas Pendidikan Ilmu Pengetahuan Sosial Universitas Pendidikan Indonesia. Jakarta.

Rizki, Puspa Andhani. 2014. Strategi Pemasaran Gula Kelapa Organik di Desa Darensari Kecamatan Bagelan Kabupaten Purworejo. Skripsi Fakultas Pertanian Universitas Sebelas Maret. Surakarta.

Sevenpri, C. Linda. 2014. QSPM and 7C's Strategy for e-SCM Implementation Strategy. International Journal of Multimedia and Ubiquitous Engineering, 9(1): 11- 18. 